\title{
FREQUENCY OF CO-MORBIDITIES IN PATIENTS WITH CHRONIC OBSTRUCTIVE PULMONARY DISEASE
}

\author{
MUHAMMAD SAQIB, TALHA MAHMUD, ABDUL SAEED KHAN, QAZI ABDUL SABOOR \\ ALI RAFIQUE MIRZA, MUHAMMAD AFAQ SARWAR \\ Federal Postgraduate Medical Institute, Shaikh Zayed Hospital, Lahore, Pakistan.
}

\begin{abstract}
Background: Chronic obstructive pulmonary disease (COPD) is one of the common respiratory conditions which involves the airways and is characterized by persistent airflow obstruction. About five percent of the adult population of the world is being affected by this disease. COPD is associated with several different comorbidities. These comorbidities increase the risk of hospital admission and affect health outcomes in COPD.

Objective: To study the frequency of comorbidities in patients with COPD.

Methods: The study was conducted at Department of Pulmonology of FPGMI, Shaikh Zayed Hospital. The duration of study was 6 months from 01-01-2019 to 30-06-2019. It was a cross sectional study, 115 were enrolled from OPD. The data were recorded in SPSS 20.0. Data were described by using frequencies and percentages and presented in tables, picharts, and bar charts.

Results: Total 115 male COPD patients who consented to participate in the study were registered in the study from OPD. The mean age of the patients was $61.09 \pm 10.8$ years. The co-morbidities were present in $84.3 \%$ patients, and the most common disease was hypertension $(65.2 \%)$ followed by ischemic heart disease (56.5\%) osteoporosis $(54.8 \%)$, cardiac failure (46.9\%), diabetes (40.0\%), anemia (36.5\%), depression (27.8\%), acid peptic disease (26.0\%) and malignancy (11.3\%). (Figure 2) Thirty-one (26.9\%) patients had single comorbidity, while $39.1 \%$ of patients had two co-morbid conditions, and $18.3 \%$ had more than two co-morbidities.

Conclusion: The co-morbidities in COPD patients are common \& most frequent comorbidities include hypertension, ischemic heart disease, diabetes, osteoporosis and depression.
\end{abstract}

Keywords: Pulmonary, COPD, Ischemic Heart Disease, Osteoporosis, Diabetes, Anemia, Depression, Malignancy

How to cite this article: Saqib M, Mahmud T, Khan AS, Saboor QA, Mirza AR, Sarwar MA. Frequency of comorbidities in patients with chronic obstructive pulmonary disease. Pak Postgrad Med J 2020;31(4): 186-189

This is an Open Access article distributed under the terms of the Creative Commons Attribution License (http://creativecommons.org/licenses/by/3.0), which permits unrestricted use, distribution, and reproduction in any medium, provided the original work is properly cited.

DOI: http://doi.org/10.51642/ppmj.v31i04.408

Correspondence to: Muhammad Saqib

Assistant Professor,

Department of Pulmonology,

Federal Postgraduate Medical Institute, Shaikh Zayed

Hospital, Lahore, Pakistan.

Email:dr.saqib.ch@gmail.com

\section{INTRODUCTION}

COPD is one of the common respiratory conditions which involves the airways and is characterized by airflow limitation. ${ }^{1-2}$ About five percent of the adult population of the world is being affected by this disease. ${ }^{3}$ Patients of COPD can have local effects of the disease as well as systemic effects. The exact mechanism of systemic effects due to COPD is not fully understood, but is believed to have relation with oxidative stress and enhanced systemic inflammation. ${ }^{4}$ Smoking which is well known risk factor for COPD. It not only causes inflammation in the lungs but also systemic inflammation. It is presumed that the systemic effects of smoking lead to development of cardiovascular diseases, metabolic disorders and malignancy. ${ }^{5}$ 


\section{ORIGINAL ARTICLE}

Different comorbidities are associated with COPD. Comorbidity is defined as a disease present with the primary disease. In case of COPD coexisting diseases may be a consequence of COPD or may have causal link with COPD. According to different studies the common comorbidities in patients with COPD are diabetes, hypertension, ischemic heart disease, heart failure, osteoporosis, cancer, anemia and depression. The comorbidities associated with COPD should be considered at the time of estimation of the social and economic burden of COPD. These comorbidities clearly affect health outcomes in COPD. ${ }^{6}$ Comorbid conditions are also associated with a higher risk of exacerbations, hospital admission and are also one of the main predictors of increased cost in COPD. ${ }^{7}$

The current study has been designed to study "Frequency of Co-Morbidities in Patients with COPD" in local population.

\section{METHODS}

It was a cross sectional study conducted at department of Pulmonology, Shaikh Zayed FPGMI, Lahore. The duration of study was 6 months from 0101-2019 to 30-06-2019. After taking the informed consent a total 115 diagnosed cases of COPD were enrolled from outpatient department of Shaikh Zayed hospital Lahore. Patients with other respiratory diseases like interstitial lung disease, bronchiectasis, allergic broncho-pulmonary aspergillosis (ABPA), sarcoidosis, Occupational lung diseases were excluded. The data were recorded in SPSS 20.0. Data were described by using frequencies and percentages and presented in tables, pi-charts, and bar charts.

\section{RESULTS}

Total 115 male COPD patients who consented to participate in the study were registered in the study from OPD. The mean age of the patients was $61.09 \pm 10.8$ years. Majority of the patients were ex-smoker, 72 (62.6\%) patients had history of cigarette smoking, 11 (9.6\%) patients were hukka smoker while $27.8 \%$ patients were both hukka \& cigarette smoker. Twenty one $(18.3 \%)$ study participants had mild COPD, 45 (39.1\%) had moderate, 39 (33.9\%) had severe while 10 $(8.7 \%)$ had very severe COPD. (Table 1 )

Fifty three percent patients had history of more than 30 pack years of smoking while $29 \%$ had smoking history between 20 and 30 pack years and $8.7 \%$ had smoking history of less than 20 pack years. (Figure 1)

The co-morbidities were present in $84.3 \%$ patients, and the most common disease was hypertension
(65.2\%) followed by ischemic heart disease $(56.5 \%)$ osteoporosis $(54.8 \%)$, cardiac failure $(46.9 \%)$, diabetes (DM) $(40.0 \%)$, anemia (36.5\%), depression $(27.8 \%)$, acid peptic disease $(26.0 \%)$ and lung cancer $(8.7 \%)$. (Figure 2) Thirty-one (26.9\%) patients had single comorbidity, while $39.1 \%$ of patients had two comorbid conditions, and $18.3 \%$ had more than two comorbidities. (Table 2)

Table.1. various characteristics of patients

\begin{tabular}{lcc}
\hline Characteristics & $\mathrm{N}$ & $\%$ \\
\hline Age & & \\
$\quad$ Less than 50 years & 10 & 8.7 \\
$\quad$ 51 to 70 years & 82 & 71.3 \\
$\quad$ More than 70 years & 23 & 20.0 \\
Type of Smoking & & \\
$\quad$ Cigarette & 72 & 62.6 \\
$\quad$ Hukka & 11 & 9.6 \\
$\quad$ Cigarette \& Hukka & 32 & 27.8 \\
FEV $_{1}$ & & \\
$\quad$ More than $80 \%$ of predicted & 21 & 18.3 \\
$\quad$ Between 50 to 80 \% of predicted & 45 & 39.1 \\
$\quad$ Between 30 to 50 \% of predicted & 39 & 33.9 \\
$\quad$ Less than 30\% of predicted & 10 & 8.7 \\
\hline
\end{tabular}

Table.2. Number of co-morbidities in COPD patients

\begin{tabular}{lcc}
\hline Co-morbidities & N & $\%$ \\
\hline Single & 31 & 26.9 \\
Two co-morbidities & 45 & 39.1 \\
More than two co-morbidities & 21 & 18.3 \\
No co-morbidity & 18 & 15.6 \\
\hline
\end{tabular}

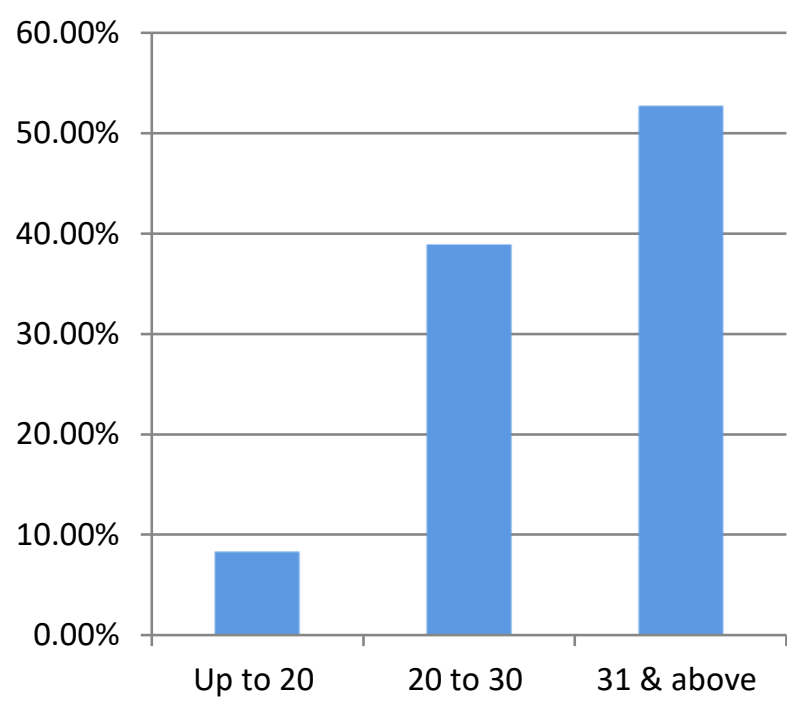

Figure.1. Pack years of smoking 


\section{ORIGINAL ARTICLE}

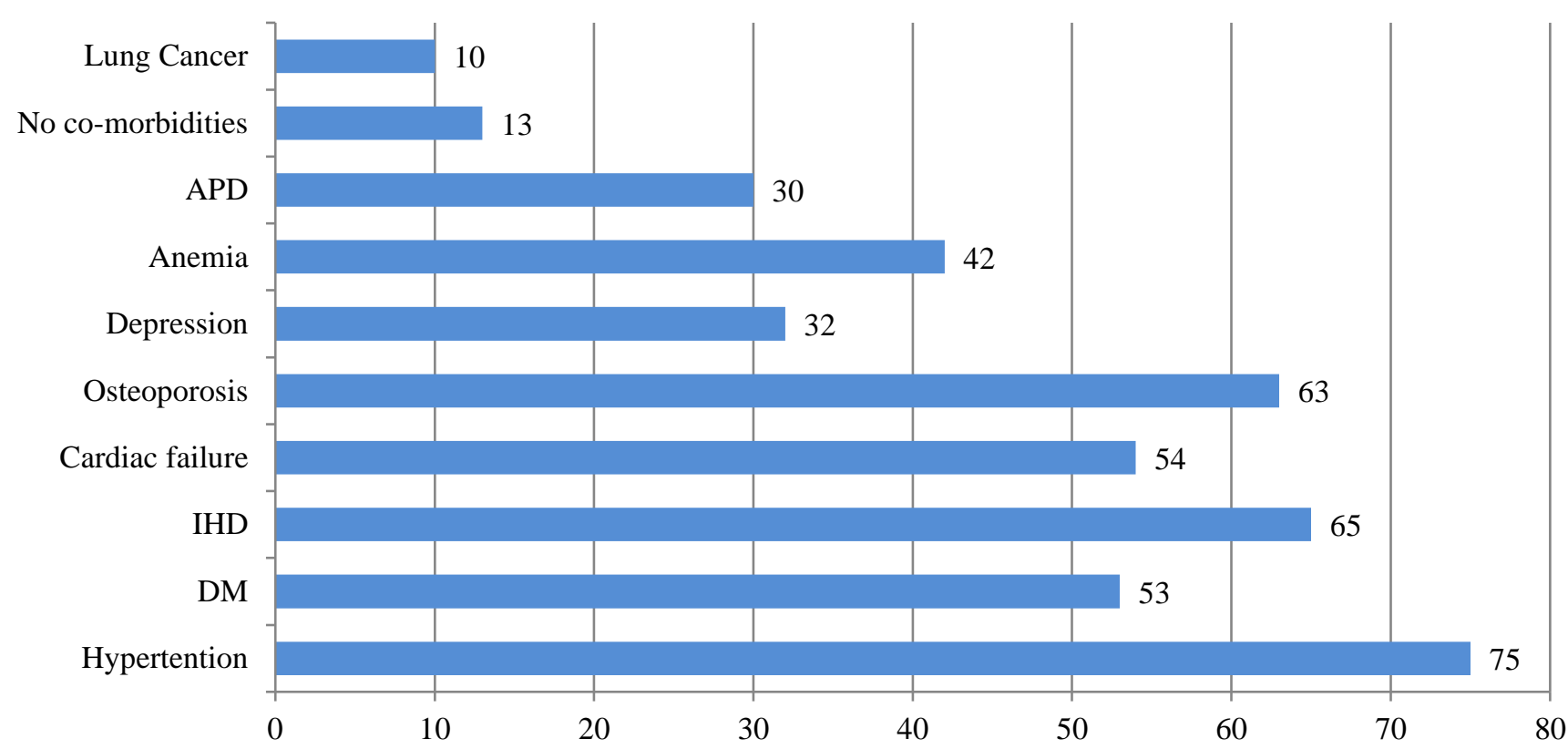

Figure.2. Co-morbidities in patients with COPD

\section{DISCUSSION}

COPD is one of the leading causes of mortality and morbidity worldwide. It causes considerable economic and social burden. Pakistan has fourth highest mortality rate in the world due to COPD with 71 deaths per $100,000 .{ }^{8}$ One of the factors which are responsible for higher mortality rate in COPD is presence of comorbidities. Some comorbid conditions may influence COPD progression and frequency of exacerbations which leads to higher costs of management ${ }^{9}$ along with higher mortality. ${ }^{10}$ Some diseases affect certain subgroups of COPD. Moreover, some chronic illnesses can influence management decision-making in COPD patients. ${ }^{11}$

The present study found that of $84.4 \%$ COPD patients had one or more co-morbidities, a study conducted by Ferrer M.et al ${ }^{12}$ in Spain also revealed that $84 \%$ of study patients have at least single co-morbid condition. In our study $26.9 \%$ patients had only one comorbidity, $39.1 \%$ patient had two co-morbidities and $18.3 \%$ patients had more than two co-morbid conditions. In analysis of patients with COPD from three studies it was found that $36 \%$ patients had one comorbidity and $30 \%$ patients had more than one comorbidity. ${ }^{13}$

The Ischemic heart disease, hypertension, cardiac failure, diabetes, osteoporosis, depression and malignancy are most common comorbid conditions seen in our study. Similar pattern of co-morbidities was seen in a study done by Yin HL et al. ${ }^{13}$

A study conducted in Beijing, China the prevalence of cardiovascular disease in COPD patients was $51.7 \%^{14}$ current study also reported high prevalence of cardiovascular diseases as ischemic heart disease was reported in $56.5 \%$ patients and $46.9 \%$ patients had cardiac failure. According to different studies depression may affect 20 to $60 \%$ of COPD patients. ${ }^{15,16}$ In our study depression was seen in $26.7 \%$ patients. About fifty five percent patients in our study had osteoporosis, whereas according to another study COPD associated with osteoporosis in $70 \%$ patients. ${ }^{17}$ Some studies has found that DM is more common in patients with COPD and in a series of studies it has been noted that DM is associated with reduced lung function. ${ }^{18} \mathrm{In}$ current study DM was seen in $40 \%$ of study population. Smoking is major risk factor for lung cancer but COPD is also an independent risk factor for lung cancer. ${ }^{5}$ In this study ten patients had bronchogenic carcinoma along with COPD. In COPD patients, comorbidities are associated with poor quality of life ${ }^{13}$ and treating the associated comorbid conditions may improve the outcomes in COPD by reducing symptoms \& exacerbations. ${ }^{19}$

Some limitation of our study includes, firstly the study enrolled only male patients due to higher smoking rates and prevalence of COPD in males, secondly it was cross sectional study and there should be longitudinal studies to see the impact of comorbidities in COPD patients.

\section{CONCLUSION}

The co-morbidities in COPD patients are common $\&$ most frequent comorbidities include hypertension, ischemic heart disease, diabetes, osteoporosis and depression. Management of comorbidities should be integral part of COPD control programs. 


\section{CONFLICT OF INTEREST}

No conflict of interest to disclose

\section{ETHICAL APPROVAL}

The study was approved from Institutional Review Board of Federal Postgraduate Medical Institute, Lahore, Pakistan.

\section{REFERENCES}

1. Buist AS, McBurnie MA, Vollmer WM. International variation in the prevalence of COPD (the BOLD Study): A population-based prevalence study. Lancet 2007; 370:741.

2. Gershon AS, Warner L, Cascagnette P. Lifetime risk of developing chronic obstructive pulmonary disease: A longitudinal population study. Lancet 2011; 378:991.

3. Centers for Disease Control and Prevention (CDC). Chronic obstructive pulmonary disease among adults-United States, 2011. MMWR Morb Mortal Wkly Rep 2012; 61:938.

4. Fabbri LM, Rabe KF. From COPD to chronic systemic inflammatory syndrome? Lancet 2007;370:797-799.

5. Petros Bakakos, Konstantinos Kostikas, Stelios Loukides. COPD and comorbidities. Pneumon 2010, 23(1):24-27

6. Mannino DM, Watt G, Hole D. The natural history of chronic obstructive pulmonary disease. Eur Respir J 2006;27:627-643.

7. Mannino DM, Thorn D, Swensen A, Holguin F. Prevalence and outcomes of diabetes, hypertension and cardiovascular disease in COPD. Eur Respir J 2008;32:962-969.

8. Ullah R, Ashraf S. Chronic obstructive lung disease: A rising problem for the world! Pak J Chest Med 2017; 23(4): 130- 133.

9. Mannino DM, Higuchi K, Yu TC. Economic burden of COPD in the presence of comorbidities. Chest 2015;148:138-150.

10. Divo M, Cote C, de Torres JP. Comorbidities and risk of mortality in patients with chronic obstructive pulmonary disease. Am J Respir Crit Care Med 2012;186:155-161.

11. Brown JP, Martinez CH. Chronic obstructive pulmonary disease comorbidities. Curr Opin Pulm Med 2016;22:113-118.

12. Ferrer M, Alonso J, Morera J. Chronic obstructive pulmonary disease stage and health-related quality of life. The Quality of Life of Chronic Obstructive Pulmonary Disease Study Group. Ann Intern Med 1997;127:1072-1079.

13. Yin HL, Yin SQ, Lin QY, Xu Y, Xu HW, Liu T. Prevalence of comorbidities in chronic obstructive pulmonary disease patients: A meta-analysis. Medicine (Baltimore). 2017;96(19):e6836. doi:10.1097/MD.0000000000006836.
14. Cui H, Miao DM, Wei ZM. Prevalence of cardiovascular disease in subjects hospitalized due to chronic obstructive pulmonary disease in Beijing from 2000 to 2010. J Geriatr Cardiol. 2012;9(1):5-10. doi:10.3724/SP.J.1263.2012.00005

15. Kunik ME. Surprisingly high prevalence of anxiety and depression in chronic breathing disorders. Chest 2005; 127: 1205-1211.

16. Schneider C, Jick SS, Bothner U. COPD and the risk of depression. Chest 2010; 137: 341-347.

17. Bolton CE, Ionescu AA, Shiels KM. Associated loss of fat-free mass and bone mineral density in chronic obstructive pulmonary disease. Am J Respir Crit Care Med 2004;170:1286-1293.

18. Ho TW, Huang CT, Ruan SY, Tsai YJ, Lai F, Yu CJ. Diabetes mellitus in patients with chronic obstructive pulmonary disease-The impact on mortality. PLoS One. 2017;12(4):e0175794. Published 2017 Apr 14. doi:10.1371/journal.pone.0175794

19. Mahmud T, Bokhari SN, Aasim M. Comparison of frequency of undiagnosed chronic obstructive pulmonary disease in current or former tobacco smokers having ischaemic heart disease. Indian $\mathbf{J}$ Chest Dis Allied Sci. 2012 Apr-Jun;54(2):111-6. PMID: 22973780.

\author{
AUTHOR'S CONTRIBUTIONS \\ MS: Concept and Design, Manuscript writing \\ TM: Supervision, Critical Review \\ ASK: Data analysis, Manuscript writing \\ QAS: Data Collection \\ ARM: Statistical Analysis \\ MAS: Critical Review
}

\section{AUTHORS}

1. Muhammad Saqib, Assistant Professor, Department of Pulmonology.

2. Talha Mahmud, Professor \& Head, Department of Pulmonology.

3. Abdul Saeed Khan, Assistant Professor, Department of ENT,

4. Qazi Abdul Saboor, Professor \& Head, Department of Cardiology.

5. Ali Rafique Mirza, Professor \& Head, Department of Plastic Surgery.

6. Muhammad Afaq Sarwar, Professor \& Head, Department of Neuro Surgery.

1-6: Shaikh Zayed Hospital, Federal Postgraduate Medical Institute, Lahore, Pakistan. 